(C)American Psychological Association, [2018]. This paper is not the copy of record and may not exactly replicate the authoritative document published in the APA journal. Please do not copy or cite without author's permission. The final article is available, upon publication, at: http://psycnet.apa.org/fulltext/2018-21052-004.html.

\title{
A Longitudinal Twin Study of Callous-Unemotional Traits during Childhood
} Running head: LONGITUDINAL TWIN CALLOUS-UNEMOTIONAL

Jeffrey Henry ${ }^{1,2}$

Ginette Dionne $^{1,2}$

Essi Viding $^{3}$

Amélie Petitclerc ${ }^{4}$

Bei Feng ${ }^{1,2}$

Frank Vitaro ${ }^{2,5}$

Mara Brendgen ${ }^{2,6}$

Richard E. Tremblay ${ }^{2,7}$

Michel Boivin $^{1,2,8}$

${ }^{1}$ School of Psychology, Laval University, Québec, QC, Canada

${ }^{2}$ Research Unit on Children's Psychosocial Maladjustment, Montreal, QC, Canada

${ }^{3}$ Division of Psychology and Language Sciences, University College London, London, UK

${ }^{4}$ Department of Medical Social Sciences, Northwestern University, Chicago, IL, US

${ }^{5}$ Department of Psycho-Education, University of Montreal, Montreal, QC, Canada

${ }^{6}$ Department of Psychology, University of Quebec in Montreal, Montreal, QC, Canada

${ }^{7}$ Department of Psychology, University of Montreal, Montreal, QC, Canada 
${ }^{8}$ Institute of Genetic, Neurobiological, and Social Foundations of Child Development, Tomsk State University, Tomsk, Russian Federation

\section{Author note}

The Quebec Newborn Twin Study (QNTS) is supported by the Social Sciences and Humanities Reseach Council of Canada, the Canadian Institutes of Health Research, the Fonds Québécois de la Recherche sur la Société et la Culture (multiple grants). These analyses were also supported by the Fonds Québécois de Recherche sur le Société et la Culture [174029, 2013SX-177862] and the Canadian Institutes of Health Research [134846] doctoral fellowships to Jeffrey Henry.

All procedures in the QNTS were approved by the ethics review boards of Laval University and St.-Justine Hospital and by the boards of the participating schools. Collection of data pertaining to the current study was approved by the ethic review board of Laval University (Comparing Indirect and Overt Aggression in Children: Early Risk Factors and Subsequent Adjustment Outcomes (approval number \#1898), The Many Ways of Suffering: Physical and Psychological Victimization Experiences Among Children (\#1899), The Genetic-Environmental Etiology of Disruptive Behavior Trajectories: A Twin Design (\#2054), The GeneticEnvironmental Etiology of Peer Relationship Difficulties and Associated Socio-Emotional Problems in Middle Childhood (\#2832)).We gratefully acknowledge the on-going contribution of families, children and teachers in the Quebec Newborn Twin Study (QNTS). We also thank Hélène Paradis for data preparation and Marie-Élyse Bertrand for project coordination. 


\begin{abstract}
Previous research indicates that genetic factors largely account for the stability of callousunemotional (CU) traits in adolescence. However, the genetic-environmental aetiology of the development of $\mathrm{CU}$ traits has not been extensively investigated in childhood, despite work showing the reliable measurement and stability of CU traits from a young age. The aim of this study was to investigate the temporal pattern of genetic and environmental aetiology of CU traits across primary school, from school entry ( 7 years) to middle ( 9 and 10 years) and late childhood (12 years). Data were collected in a population sample of twins composed of 662 twin pairs (Quebec Newborn Twin Study). CU traits were reported by teachers and analyzed using a biometric latent growth curve model and a Cholesky decomposition model. Latent growth curve analyses revealed that genetic factors explain most of the variance in the intercept of CU traits. Individual differences in change over time were not significant. The Cholesky model revealed that genetic factors at 7 years had enduring contributions to CU traits at 9, 10 and 12 years. New, modest genetic contributions appeared at 9 and 10 years. Non-shared environmental contributions were generally age-specific. No shared environmental contributions were detected. In sum, both modeling approaches showed that genetic factors underlie CU traits during childhood. Initial and new genetic contributions arise during this period. Environments have substantial contributions, over and above genetic factors. Future research should investigate the source of genetic risk associated with CU traits.

Keywords: Callous-unemotional traits, Genetic-environmental aetiology, Cholesky decomposition, Linear latent growth curve model, Twin studies.
\end{abstract}




\section{General scientific summary}

- Early genetic factors account for a substantial part of CU traits' development in schoolage childhood, but new genetic factors emerge later during this period. Environmental factors also have contributions, over and above genetic factors.

- There is a need to understand the nature of genetic risk associated with CU traits, especially with regard to how genetic factors vary over time.

- Late interventions aiming to reduce CU traits could be effective as targeting the right risk factors at the right time is critical. 


\section{Introduction}

Callous-unemotional (CU) traits are defined by a lack of empathy and guilt, as well as superficial affect (Frick, 2009). These features are at the affective core of adult psychopathy (Cleckley, 1976) and have been used to extend this construct to youths. There is substantial evidence highlighting the role of CU traits in the developmental course of severe antisocial behavior (Frick, Ray, Thornton, \& Kahn, 2014). Indeed, early elevated CU traits are associated with severe, aggressive, stable and recalcitrant patterns of conduct problems (Christian, Frick, Hill, Tyler \& Frazer, 1997; Frick, Cornell, Barry \& Dane, 2003a; Frick et al., 2003b, Frick, Stickle, Dandreaux, Farrell \& Kimonis, 2005; Vincent, Vitacco, Grisso \& Corrado, 2003; Frick \& Dickens, 2006), and involve a heightened risk for adult psychopathy (Barry et al., 2000; Loney, Taylor, Butler \& Iacono, 2007). For these reasons, clarifying the aetiological factors underlying the development of these traits is warranted.

In this regard, twin studies are informative. They allow for statistically disentangling sources of variance attributable to genetic and environmental factors. Past twin reports have shown moderate to strong genetic contributions (i.e., heritability) to youths' CU traits (43-70\%; see Viding \& McCrory, 2012). There is increasing consensus that genetic vulnerability for CU traits predisposes to a neurocognitive profile characterised by diminished responsivity to other people's emotions, including their distress (Viding \& McCrory, 2015). In turn, this disposition possibly accounts for stable and enduring deficits in empathy and normative guilt (e.g., Blair, 2015; Frick et al., 2014).

While CU traits have been posited as reflecting a stable temperamental feature, to our knowledge only four twin studies have directly investigated the genetic-environmental aetiology of the stability of these traits. These studies have found that genetic factors play an important 
role in the stability of $\mathrm{CU}$ traits in preschool and adolescence. Blonigen, Hicks, Krueger, Patrick and Iacono (2006) have reported that $58 \%$ of the stability in CU traits between 17 and 24 years was attributable to common genetic variance between the two time points. Forsman, Lichtenstein, Andershed and Larsson (2008) found that the genetic correlation between CU traits at 16 and 19 years was .82. In preschool children, a genetic correlation of .65 was found between CU traits at 2 and 3 years (Flom \& Saudino, 2016). Lastly, using a trajectory approach, another study found that, in boys, membership in all trajectories of CU traits - stable-high, increasing, decreasing, and stable-low - is strongly heritable, although in girls shared environmental factors were more important for determining membership in the stable-high trajectory (Fontaine, Rijsdijk, McCrory \& Viding, 2010).

Current research is thus convergent, but not without limitations. First, all of the abovementioned studies have used the same rater to assess CU traits at each wave, thus enhancing the prospect of inflated correlations through shared method variance. In the present study, we used independent raters across waves in order to reduce the prospect of shared method variance. Second, these studies did not extensively cover childhood. Indeed, two of them (Blonigen et al., 2006; Forsman et al., 2008) have looked at CU traits between mid-adolescence and early adulthood. Yet, initial signs of CU traits can be reliably assessed at the age when children transition to school (4-7 years; e.g., Kimonis et al., 2016), a period that coincides with new stressors and exposition to peers that may influence the expression of genetic (or environmental) vulnerability for CU traits. Past research also indicates that CU traits in childhood robustly predict antisocial and criminal behavior in adulthood, even after controlling for severity and age of onset of conduct problems (McMahon, Witkiewitz, \& Kotler, 2010). Moreover, longitudinal studies indicate that CU traits are as phenotypically stable as other youth disorders from 12-13 
years onwards (Loeber, Pardini, Stouthamer-Loeber, Hipwell \& Sembower. 2009; Lynam, Caspi, Moffitt, Loeber \& Stouthamer-Loeber, 2007). The aforementioned Fontaine et al.'s study (2010) investigated childhood trajectories of CU traits from 7 to 12 years, but did not document the extent to which specific time-point measures have a shared aetiology. Finally, one study focused on preschool (Flom \& Saudino, 2016). The transition into late childhood however seems important for $\mathrm{CU}$ traits as they are subject to change during this period (Baskin-Sommers, Waller, Fish \& Hyde, 2015; Fanti, Colins, Andershed \& Sikki, 2016; Fontaine et al., 2010). There is thus a gap in the knowledge about the aetiology of the development of CU traits for the childhood period starting with school entry.

The goal of the present study was to examine the genetic and environmental sources of individual differences in the development of CU traits between school entry and late childhood (i.e., 7, 9, 10 and 12 years). When examining the genetic-environmental underpinnings of stability and change in a heritable phenotype such as CU traits, several non-mutually exclusive patterns can be revealed. For instance, a genetic set-point model (Lacourse et al., 2014) would be supported if a single set of early-emerging genetic factors accounts for the level of CU traits over time. Genetic continuity across this period might be expected as CU traits tend to emerge in early childhood (Kimonis et al., 2016), and are phenotypically stable (Loeber et al., 2009). Many twin studies have indeed found that genetic factors substantially contribute to the stability of behaviors associated with CU traits (e.g., Burt, McGue, Carter, \& Iacono, 2007; Lacourse et al., 2014; Petitclerc, Boivin, Dionne, Pérusse \& Tremblay, 2011). In these studies, environmental contributions tend to be age-specific and to account for within-family differences, rather than similarities. 
While the stability could be driven by early genetic factors, new genetic factors may also emerge across childhood. These effects could be wave-specific or enduring over time, which would be in line with a genetic maturation model (Lacourse et al., 2014). Similar processes can also occur for environmental effects. Trajectory analysis has also shown that, at least for a subset of children, CU traits are not stable across childhood, increasing or decreasing between the ages of 7 and 12 (Fontaine et al., 2010). Thus, specific genetic contributions could emerge later in childhood, as risk genes for CU traits may be expressed in response to several stressors such as increasing exposure to deviant peers (Kimonis, Frick, \& Barry, 2004) or the onset of puberty. It is also possible that certain genetic effects come 'on line' at a later point because of biologically driven developmental cascades (see Pingault, Rijsdijk, Zheng, Plomin, \& Viding, 2015).

In the present study, two complementary approaches were used to more fully document the nature of genetic-environmental contributions to CU traits. First, the aetiological factors underlying the systematic stability (i.e., intercept) and change (i.e., slope) in CU traits throughout childhood were estimated through a biometric latent growth curve model. This highly flexible approach focuses on between-person differences in within-person change, and derives latent estimates based on all the longitudinal data available (McArdle \& Epstein, 1987). In latent growth curve modelling, a heritable component to the intercept implies genetic contributions to thein systematic stability of CU traits. Heritability of the slope implies genetic contributions to the variability of linear patterns of change in CU traits. In other words, this analysis enables us to assess the degree to which individual differences in the systematic stability and change of CU traits are due to genetic (or environmental) factors. A genetic set point hypothesis is supported when a strong genetic contribution to the intercept is found, along with a weak genetic 
contribution to the slope and/or residuals. Alternately, a strong genetic contribution to the slope, and/or age-specific genetic residuals would support a genetic maturation model.

This general approach was followed by a more in-depth approach, the Cholesky decomposition, based on a time-specific analysis of the genetic and environmental contributions to stability and change in CU traits. This will allow documenting the extent to which initial genetic and environmental contributions persist over time (i.e., genetic set-point model), and whether and when new factors emerge to explain these differences over time (i.e., genetic maturation model). This approach more precisely documents the timing and dynamic of the genetic and environmental underpinnings of CU traits over time.

\section{Methods}

Participants. Participants were part of an ongoing longitudinal study of a populationbased sample of twins from greater Montreal, Canada (Quebec Newborn Twin Study [QNTS]) who were recruited at birth between November 1995 and July 1998 ( $N=662$ twin pairs; Boivin et al., 2013a). Zygosity of twin pairs was assessed through detailed ratings at 20 months (Goldsmith, 1991) and confirmed in $96 \%$ by genotyping (Forget-Dubois et al., 2003). Parental consent was obtained for all participating families, as well as teacher consent for those who rated CU traits. Titular teachers rated the participating twins' behaviors. Data collections took place in the spring of the school year to ensure that teachers were well acquainted with the twins. At each wave, most twins of the same family did not share classrooms $(76 \%$ were in different classroom at both ages 7 years and 9 years, $70 \%$ at 10 years, and $60 \%$ at 12 years). More details on the sample are provided in the Other Supplementary Material. The number of twins varied across the four $\mathrm{CU}$ waves $(7$ years $-\mathrm{MZ}=184, \mathrm{DZ}=244 ; 9$ years $-\mathrm{MZ}=166, \mathrm{DZ}=227 ; 10$ years $-\mathrm{MZ}$ 
$=168, \mathrm{DZ}=233 ; 12$ Years $-\mathrm{MZ}=136, \mathrm{DZ}=205)$. Opposite-sex DZ twins were included in our analyses to maximize power.

Measurement of callous-unemotional traits. CU traits were measured at 7, 9, 10 and 12 years via five teacher-rated items. These items were assessed on a 3-point Likert scale $(0=$ never; $1=$ sometimes; $2=$ often or always). Items were selected on the basis of their relevance to the $\mathrm{CU}$ construct in previously validated measures. Three of the selected items were featured in the Inventory of Callous-Unemotional Traits (Frick, 2003): "he/she did not seem guilty after misbehaving", "his/her emotions appeared superficial", "he/she has been insensitive of other people's feelings". Two others were taken from the Antisocial Process Screening Device (APSD; Frick \& Hare, 2001): "he/she did not keep promises", "he/she used or conned others". Confirmatory factor analyses supported a one-factor structure metrically and structurally invariant over time (see Other Supplementary Material). Mean scores were thus computed by averaging the items, with a high mean score indicating high levels of CU traits. Internal consistencies, based on one twin per pair, were acceptable $(\alpha=.73-.76)$. The resulting scales showed expected associations with relevant criteria (see Other Supplementary Material).

\section{Statistical analysis.}

Phenotypic analyses. Stability of CU traits was estimated with Pearson's correlations ( $p$ $<.05$ ), and we tested a latent growth curve model to extract, from the four CU waves, the intercept and the linear slope in CU traits. Slope factor loadings were fixed to 0 for the first wave, and to 1, 1.5 and 2.5 for the second, third and fourth waves, reflecting time in years. Intercept factor loadings were fixed to 1 ; equivalent loadings for all waves indicate that the intercept is a common factor, thus capturing systematic stability over time. Residuals were also estimated at each wave and were allowed to covary between MZ and DZ pairs. 
Genetic analyses. The twin design is based on the comparison of similarities between $\mathrm{MZ}$ twins, who share $100 \%$ of their genes, and DZ twins, who share on average $50 \%$ of their genes, on a given phenotype. Assuming children in a family are exposed to a similar environment regardless of zygosity, heritability (i.e., genetic contributions) is indicated when MZ twins are significantly more similar than DZ twins. Equivalent similarity across MZ and DZ twins indicates shared environmental variance. At a univariate level, the twin procedure allows for disentangling the variance into three sources: additive genetic (A), shared environmental (C) and non-shared environmental (E). Controlling for genetic factors, shared environment reflects similarities between twins of the same family, whereas non-shared environment signals differences between them. Measurement error is also comprised in the non-shared environment parameter. At the multivariate level, the variances and covariances between phenotypes are decomposed into their additive genetic, shared environment, and non-shared environment factors. This provides an estimation of the relative contribution of genetic and environmental factors to the associations between these constructs (Plomin, DeFries, Knopik, \& Neiderhiser, 2013).

In the present study, we tested univariate and multivariate ACE models of CU traits at 7, 9, 10 and 12 years. Univariate models gave preliminary estimates of genetic-environmental contributions on the individual CU measures. Multivariate models were then carried out in order to investigate the aetiology of the development of CU traits over this period. The first multivariate model was a latent growth curve model delineating two latent factors: the intercept, referring to systematic stability in CU traits, and the slope, representing the rate of increase or decrease with age. This model also includes the covariance between the intercept and the slope. The genetic and environmental sources of variance of each wave-specific residual were also 
decomposed. Then, we used a Cholesky decomposition model of the phenotypic variance at all four waves. This model specifies genetic-environmental sources of variance that are timespecific and/or shared between the waves (for more details on this model, see the Results section).

The Statistical Package for the Social Sciences (SPSS Version 20.0, IBM Corp, 2011) was used to compute descriptive statistics and Pearson's correlations. Intraclass correlations, latent growth curve analysis and twin modelling were performed using Mplus (Version 8; Muthén \& Muthén, 1998-2017). As expected, all CU scores were skewed to the 'never' end (see Table 1). We thus used a robust maximum likelihood estimator (MLR) to allow the use of all available data while remaining robust to non-normality. Model fit was assessed using the scaled likelihood-ratio tests, Akaike's Information Criterion (AIC), the Bayesian Information Criterion (BIC), the Comparative Fit Index (CFI) and the Root Mean Square Error of Approximation (RMSEA). The scaled likelihood-ratio test, the AIC and the BIC indicate relative fit (Akaike, 1987). The CFI indicates absolute fit ( $\geq .95$; Hu \& Bentler, 1999), as the RMSEA, which is unaffected by the model size $(\leq .06 ; \mathrm{Hu} \&$ Bentler, 1999). For all genetic models, statistical significance was determined at $95 \%$ confidence intervals. Biometric models were conducted on age- and sex-regressed CU scores to remove any similarity between twins by virtue of being the same age and same sex, which may affect the results as opposite-sex DZ twins were included.

\section{Results}

Phenotypic analyses. Table 1 displays the descriptive statistics and number of participants at each wave. The mean values (i.e., .24, .27, .25, .23) suggest no significant change on average level of CU traits between 7 and 12 years. The correlation was .39 $(p<.001)$ between the first and second waves, $.50(p<.001)$ between the second and third waves and $.42(p<.001)$ 
between the third and fourth waves. The correlation was $.37(p<.001)$ between the first and third waves, $.27(p<.001)$ between the first and the fourth waves and $.35(p<.001$ between the second and the fourth waves. Intra-class correlations were greater for the MZ than the DZ pairs at each wave, suggesting significant heritability: 7 years $-\mathrm{ICC}_{\mathrm{mz}}=.46, \mathrm{ICC}_{\mathrm{dz}}=.23$; 9 years $\mathrm{ICC}_{\mathrm{mz}}=.59, \mathrm{ICC}_{\mathrm{dz}}=.30 ; 10$ years $-\mathrm{ICC}_{\mathrm{mz}}=.39, \mathrm{ICC}_{\mathrm{dz}}=.20 ; 12$ years $-\mathrm{ICC}_{\mathrm{mz}}=.48, \mathrm{ICC}_{\mathrm{dz}}=$ .31. Stability coefficients tended to be similar in MZ ( $r=.48-.50)$ vs. DZ twins $(r=.32-.50)$.

\section{(Insert Table 1 here)}

In the linear latent growth curve model, the intercept mean differed significantly from zero $(\mathrm{I}=.27,95 \% \mathrm{CI}=.24-.30)$, but not the slope mean $(\mathrm{S}=.00,95 \% \mathrm{CI}=-.01-.02)$. The intercept variance differed significantly from zero $\left(\sigma_{\mathrm{i}}{ }^{2}=.05,95 \% \mathrm{CI}=.03-.08\right)$, but not the slope variance $\left(\sigma_{\mathrm{s}}^{2}=.00,95 \% \mathrm{CI}=-.00-.00\right)$. The intercept and the rate of change were unrelated $(-.01,95 \% \mathrm{CI}=-.01-.01)$.

Genetic analyses. Full and nested univariate ACE models were tested on the CU scores (see Table 2). All four models indicated significant heritability of CU traits. The best-fitting model for all four waves was an 'AE' model, where both genetic and non-shared environmental factors accounted for individual differences. Fixing ' $\mathrm{C}$ ' components to zero resulted in betterfitting models.

\section{(Insert Table 2 here)}

Both latent growth curve and the Cholesky decomposition models fit the data well (see Table 3). Results from the latent growth curve model are presented in Table 4 . The geneticenvironmental aetiology of both latent factors and wave-specific residuals of the latent growth curve model was assessed (see Figure 1). Contrary to the Cholesky decomposition, we initially retained all ' $\mathrm{C}$ ' components as the inclusion of latent factors in the model may affect the partition 
of variance among the 'A', 'C' and 'E' components (e.g., lower 'E' was expected as latent factors include less error than observed variables). In the final model, several parameters were fixed to 0 because they were not statistically significant (see Table 4).

$$
\begin{aligned}
& \text { (Insert Table } 3 \text { here) } \\
& \text { (Insert Table } 4 \text { here) } \\
& \text { (Insert Figure } 1 \text { here) }
\end{aligned}
$$

Individual differences in the intercept were largely explained by genetic factors (89\%; see Table 4). Other sources of variance - i.e., shared (6\%) and non-shared environment (5\%) did not contribute significantly. Parameters related to rate of change are not interpreted considering the absence of phenotypic change. The latent factors explained 42, 47, 51 and $61 \%$ of the variance at grades 1, 3, 4 and 6, respectively. In grade 1, 38\% of total variance was explained by genetic factors accounted by the intercept; in grade 3, it was $37 \%$; in grade $4,36 \%$, and in grade $6,32 \%$ (not shown in Table 4). Wave-specific residuals were mostly accounted for by non-shared environment and, to some extent, genetic factors. There was no shared aetiology between the intercept and the slope, which was expected given their absence of phenotypic association. We then tested the Cholesky decomposition of the four CU waves (see Table 5, as well as eTable4 and eFigure1 in the Other Supplementary Material). This model included: 1) genetic variance at 9 years shared with the 7-year wave (under the A1 column); 2) genetic variance at 10 years shared with the 7- (A1 column) and 9-year waves (A2 column); 3) genetic variance at 12 years shared with the 7- (A1 column), 9- (A2 column) and 10-year waves (A3 column); and finally 4) genetic variance unique to 9 (A2 column), 10 (A3 column) and 12 years (A4 column), respectively.. Similar decompositions are presented for the non-shared environmental components. 
This analysis revealed a significant extension over time of initial genetic contributions: $49 \%$ of the genetic variance of CU traits at 9 years was shared with CU traits at 7 years; the remaining $51 \%$ of its genetic variance was independent. Similarly, 10-year CU traits shared $68 \%$ of their genetic variance with 7-year traits, with the remaining genetic variance either shared with 9-year CU traits (12\%) or independent (19\%). The 12-year CU traits shared $23 \%$ of their genetic variance with 7-year CU traits, and $27 \%$ with the 9-year CU traits, with the remaining variance either shared with 10-year CU traits $(27 \%)$ or independent $(25 \%)$. Significant timespecific genetic variance was observed at 9 and 10 years. Non-shared environmental variance was entirely time-specific. Overall, the associations between the $\mathrm{CU}$ waves were mainly accounted for by genetic factors occurring at 7 years. However, new genetic factors also emerged at ages 9 and 10 years; some of the 9-year genetic factors persisted until age 12 years.

We also carried out the biometric models using a Full Information Maximum Likelihood estimator and log-transformed CU variables and found similar results, with the exception of a slightly higher shared environment parameter on the intercept (data not shown).

(Insert Table 5 here)

\section{Discussion}

The aim of the present study was to investigate the genetic and environmental aetiology of $\mathrm{CU}$ traits from 7 to 12 years of age. To that end, we combined results from two multivariate genetic models, one examining general developmental trends in CU traits (i.e., biometric latent growth curve model), the other providing a time-specific analysis of the genetic-environmental aetiology of CU traits (i.e., Cholesky decompositions). The phenotypic analyses first revealed no general change in $\mathrm{CU}$ traits between 7 and 12 years. Genetic modelling revealed that both early 
and new genetic factors were important in accounting for the development of CU traits during this period. Indeed, latent growth curve analyses showed that individual differences in systematic stability (i.e., intercept) of CU traits (7 years) were mainly accounted for by genetic factors. Genetic contributions to age-specific residuals were also observed. In line with these results, Cholesky decompositions showed that genetic contributions to CU traits at 7 years persisted through to 12 years, and that new genetic contributions also occurred at 9 and 10 years, with genetic contributions at 9 years enduring through to 12 years. Non-shared environmental contributions were significant at each wave, but essentially age-specific. We discuss each result in more detail.

Phenotypic results. The moderate stability of individual differences in CU traits is in line with results from previous studies on these traits during school-age childhood (Barker \& Salekin, 2012; Barry, Barry, Deming \& Lochman, 2008; Pardini, Lochman \& Powell, 2007; van Baardewijk, Vermeiren, Stegge \& Doreleijers, 2011). These stability estimates are remarkable considering distinct teachers rated CU traits at each wave.

Moreover, we found that individual differences in the intercept of CU traits were substantial, which is consistent with previous research documenting reliable signs of CU traits as early as in the preschool years (e.g., Kimonis et al., 2016). However, no change pattern was found in CU traits between 7 and 12 years. It may appear that this last finding contradicts Fontaine et al. (2010), who reported both increasing and decreasing trajectories of CU traits during this age period. However, the analytic approach used by Fontaine et al. (2010) focused on individual trajectories, whereas the present ones refer to the sample mean level of CU traits over time. Therefore, the current results do not necessarily suggest the absence of change in 
subgroups of children; they only indicate that there may not be a general trend of change in CU traits during this period.

Aetiological results. In both multivariate genetic models, genetic factors were the main source of variance in CU traits, a finding consistent with previous research (Viding \& McCrory, 2012). The present study also provided a more detailed evaluation of how these contributions unfold over time. Indeed, the results of genetic modelling provided some support for both the genetic set point and the genetic maturation hypotheses. Genetic factors largely explained individual differences in the intercept of CU traits, and the Cholesky decompositions confirmed the predominant role of genetic factors as substantial genetic variance was found at all developmental time-points.

The latent growth curve model highlighted strong genetic contributions to the intercept, which is an estimation of systematic stability of CU traits. Moreover, the Cholesky decomposition indicated that the genetic factors initially associated with CU traits at 7 years accounted for a substantial proportion of later CU traits, and to a comparable extent to what was found in studies conducted on preschoolers (Flom \& Saudino, 2016) and adolescents (Blonigen et al., 2006; Forsman et al., 2008). These results supported the genetic set point hypothesis Yet, the Cholesky decomposition revealed new genetic contributions at 9 and 10 years, with some genetic factors at 9 years enduring through to 12 years; this directly points to the genetic maturation hypothesis. Other results from the latent growth curve model are consistent with the Cholesky results by suggesting that new genetic contributions emerge after 7 years. Indeed, significant genetic contributions were found on the CU residuals at 9 years, indicating that some genetic processes occurring at this age were not accounted for by the intercept. In brief, although 
initial genetic factors largely explained developmental trends in CU traits, other classes of genetic factors also seemed to be involved throughout childhood.

The finding of a persistent genetic vulnerability apparent as early as age 7 and likely emerging during the preschool years supports the current state of knowledge. Indeed, recent reports have shown that CU traits can be reliably assessed during preschool (Kimonis et al., 2016) and are heritable by age 5 (Tuvblad, Fanti, Andershed, Colins \& Larsson, 2016). However, our results also suggest that new, distinct genetic contributions emerge later during childhood. These new genetic contributions could be accounted for by several processes.

For instance, complex transactions between genetic vulnerability and putative environments playing a role in $\mathrm{CU}$ traits at these ages could occur. Peer socialization is increasingly prominent as children enter adolescence, and deviant peer affiliation is known to be robustly associated with CU traits (e.g., Kimonis et al., 2004). Therefore, the emergence of new genetic contributions could reflect increasing exposure to deviant peers activating genes involved in the development of CU traits (i.e., gene-environment interaction; Brendgen, Ouellet-Morin, \& Boivin [in press]). As parental supervision decreases in the wake of adolescence, this could also mean that peer and family factors do not activate the same classes of genes related to CU traits. Children at genetic risk for $\mathrm{CU}$ traits could also elicit specific reactions from their peer environment; these reactions, such as bullying and victimization, could in turn consolidate the development of CU traits (i.e., evocative gene-environment correlation; see Boivin et al., 2013b). These children may also structure their peer environments - i.e., select deviant peers and groups - as a function of their genetic features (i.e., active gene-environment correlation), and may be more likely to do so after 7 years. 
Moreover, distinct classes of risk genes could be expressed later in development. In this regard, our current knowledge of the genomic underpinnings of CU traits is limited. Several genes have been linked to CU traits (e.g., Beitchman et al., 2012; Fowler et al., 2009), but none of their variants has been implicated in genome-wide analyses of CU traits (Viding et al., 2010, 2013). A more profitable avenue in the short-term would be to examine how genetic factors manifest more directly through cognitive-affective endophenotypes, such as atypical affective processing (see Viding \& McCrory, 2015), with particular attention to how these endophenotypes' contributions to CU traits vary in earlier vs. later childhood.

In the Cholesky decomposition, non-shared environmental factors consistently accounted for variance in $\mathrm{CU}$ traits, over and above the multi-faceted genetic contributions. This is in line with past research on CU traits (see Viding \& McCrory, 2012) which suggested that non-shared environment generally accounts for individual differences unaccounted for by genetic factors. However, these non-shared environmental sources of variance were entirely age-specific. It is also noteworthy that non-shared environmental contributions were weaker in the latent growth curve model than in the Cholesky decomposition. The use of latent factors in the growth curve model may have reduced measurement error, enabling a more accurate account of the contribution of non-shared environmental factors, as well as a more reliable detection of the genetic component. Taken together, these results suggest that non-shared environment does contribute to the development of CU traits, but some of its contributions may reflect measurement error. In support of this idea, one previous study failed to demonstrate a non-shared environmental effect of negative parental discipline on $\mathrm{CU}$ traits between ages 7 and 12, although this effect was demonstrated for conduct problems (Viding, Fontaine, Oliver, \& Plomin, 2009). 
Past reports have found non-shared environmental factors to substantially account for stability of CU traits between mid- and late adolescence (Blonigen et al., 2006; Forsman et al., 2008). As stated earlier, peer experiences become increasingly predominant during adolescence. It is possible that the non-shared environments susceptible to affect $\mathrm{CU}$ traits at 12 years are more likely to be peer-related (e.g., deviant peers), while such experiences affecting CU traits in earlier years could mainly lie in the caregiving environment (e.g., child-specific parenting other than negative discipline). Non-shared environmental contributions should however be more similar between CU measures throughout adolescence, when the developmental role of peer experiences peaks. Moreover, past studies on adolescents have relied on the same informant, i.e., self-report, to assess CU traits at multiple ages; this may have artificially inflated non-shared environmental associations through common measurement error.

Strengths and limitations. The present study has a particular strength in relying on independent raters to assess $\mathrm{CU}$ traits at each age, thereby reducing the prospect of shared method variance. Different teachers provided the data at each wave, and there were also substantial within-pair differences in raters as most twins did not share classrooms. The study also made a significant contribution by focusing on putative critical periods for the development of CU traits. However, several limitations should be noted. First, we did not find any phenotypic variance around the rate of change of CU traits; therefore, we were limited in the exploration of its aetiology.. This may in part be due to suboptimal sensitivity of our CU measure, on account of its limited number of items (five) and narrow distribution (three levels). These limitations of our CU scales, as well as their non-normal distributions, could also have increased measurement error and led to an under-estimation of stability of CU traits. Past studies have indeed found slightly higher CU stabilities for a similar period with more detailed teacher assessments (e.g., 
Barry et al., 2008; Pardini et al., 2007). Limited availability of relevant items was a practical challenge that could not be bypassed. Fortunately, the use of a robust maximum likelihood estimator in twin modelling mitigated the effect of the univariate non-normalities. It is nevertheless common in population-based samples to have non-normal distributions (mainly due to low endorsement) for psychopathological constructs. Also, despite the limitations inherent to short and non-normal scales, several statistics were indicative of limited measurement error. For instance, the internal consistencies were acceptable and similar or better than those reported in past studies (Blonigen et al., 2006; Flom \& Saudino, 2016; Forsman et al., 2008). Moreover, the 'E' parameters (which includes measurement error) in the ACE models were comparable to those obtained in past twin studies which used more detailed assessments of CU traits (Viding \& McCrory, 2012). It should however be noted that our specific pool of CU items has not had not been previously tested for its validity. The Other Supplementary Material presents evidence for its unidimensionality, temporal invariance over childhood and convergent validity, but our results will still need to be replicated.

Conclusion. Our findings show that genetic vulnerability for CU traits likely emerges early in development, and that some of it persists at least until late childhood. This highlights the importance of the preschool period for screening and prevention of CU traits. CU traits also involve some distinct genetic and environmental influences depending on the period of interest. This indicates that prevention and intervention may need to be targeted at multiple time points to counter risk trajectories. Further research should focus on the actual differences between 7-, 9-, 10- and 12-year CU traits with regard to individual and social correlates. This has the potential to inform theoretical models in a way that helps identify multiple sensitive periods for the development of CU traits. The present data suggest that partly distinct individual and social 
factors exert their influence on the development of CU traits depending on the child's age (e.g., parenting in early childhood, peer relations in later childhood); targeting the right factors at the right time is no doubt critical for the success of interventions. It is also important to conduct more research to understand the nature of the gene-environment interplay in relation to CU traits, as well as the challenges that gene-environment correlation may pose for therapeutic interventions. For instance, if part of the parenting-CU traits association in early childhood reflects family-wide genetic risk (i.e., passive gene-environment correlation), we need to better understand intergenerational risk profiles, and how those contribute to family interaction patterns. Similarly, genetically mediated personal characteristics may partly determine to what kinds peer environments a child is exposed to (i.e., evocative and selective gene-environment correlation).

Finally, it is noteworthy that most CU items used in the current study are also valid indicators of the low Agreeableness trait from the Five Factor Model (Costa \& McCrae, 1992). Accordingly, several studies have shown that CU traits and low Agreeableness overlap substantially (e.g., Assary, Salekin, \& Barker, 2015; see Frick \& Ray, 2014). The present results should therefore be placed in a larger trait perspective; they should be replicated with normative traits such as Agreeableness, and efforts should be put towards determining whether genetically informative results pertaining to $\mathrm{CU}$ traits have resonance in normal personality functioning. 


\section{References}

Akaike, H. (1987). Factor analysis and AIC. Psychometrika, 52, 317-332.

Assary, E., Salekin, R. T., \& Barker, E. D. (2015). Big-Five and Callous-unemotional Traits in Preschoolers. Journal of Psychopathology and Behavioral Assessment, 36, 371-379. doi: 10.1007/s10862-014-9471-9

Barker, E. D., \& Salekin, R. T. (2012). Irritable oppositional defiance and callous-unemotional traits: is the association partially explained by peer victimization? Journal of Child Psychology and Psychiatry, 53, 1167-1175. doi:10.1111/j.1469-7610.2012.02579.x

Barry, C. T., Frick, P. J., DeShazo, T. M., McCoy, M., Ellis, M., \& Loney, B. R. (2000). The importance of callous-unemotional traits for extending the concept of psychopathy to children. Journal of Abnormal Psychology, 109, 335-340. doi:10.1037/0021843X.109.2.335

Barry, T. D., Barry, C. T., Deming, A. M., \& Lochman, J.E. (2008). Stability of psychopathic characteristics in childhood: the influence of social relationships. Criminal Justice and Behavior, 35, 244-262. doi:10.1177/0093854807310508

Baskin-Sommers, A. R., Waller, R., Fish, A. M, \& Hyde, L. W. (2015). Callous-unemotional traits trajectories interact with earlier conduct problems and executive control to predict violence and substance use among high-risk male adolescents. Journal of Abnormal Child Psychology, 43, 1529-1541. doi:10.1007/s10802-015-0041-8

Beitchman, J. H., Zai, C., Muir, K., Berall, L., Nowrouzi-Kia, B., Choi, E., \& Kennedy, J. L. (2012). European Child and Adolescent Psychiatry, 21, 125,132. doi:10.1007/s00787-0120240-6 
Blair, R. J. R. (2015). Empathic dysfunction in psychopathic individuals. In T. Farrow \& P. Woodruff (Eds), Empathy in Mental Illness (pp. 3-16). Cambridge, UK: Cambridge University Press. doi:10.1017/CBO9780511543753.002

Blonigen, D. M., Hicks, B. M., Kruger, R. F., Patrick, C. P., \& Iacono, W. G. (2006). Continuity and change in psychopathic traits as measured via normal-range personality: A longitudinal-biometric study. Journal of Abnormal Psychology, 115, 85-95. doi:10.1037/0021-843X.115.1.85

Boivin, M., Brendgen, M., Dionne, G., Dubois, L., Pérusse, D., Robaey, P., Tremblay, R.E., \& Vitaro, F. (2013a). The Quebec Newborn Twin Study into adolescence: 15 years later. Twin Research and Human Genetics, 16, 64-69. doi:10.1017/thg.2012.129

Boivin, M., Brendgen, M., Vitaro, F., Forget-Dubois, N., Feng, B., Tremblay, R. E., \& Dionne, G. (2013b). Evidence of gene-environment correlation for peer difficulties: Disruptive behaviors predict early peer relation difficulties in school through genetic effects. Development and Psychopathology, 25, 79-92. doi:10.1017/S0954579412000910

Brendgen, M., Ouellet-Morin, I., \& Boivin, M. (in press). Peer relations and psychosocial development: Perspectives from genetic approaches. In W.W. Bukowski, B. Laursen, and K.H. Rubin (Eds.), Peer interactions, relationships and groups. New York: Cambridge University Press.

Burt, S. A., McGue, M., Carter, L. A., \& Iacono, W. G., (2007). The different origins of stability and change in antisocial personality disorder symptoms. Psychological Medicine, 37, 27 38. doi: 10.1017/S0033291706009020

Christian, R., Frick, P. J., Hill, N., Tyler, L. A., \& Frazer, D. (1997). Psychopathy and conduct problems in children: II. Subtyping children with conduct problems based on their 
interpersonal and affective style. Journal of the American Academy of Child and Adolescent Psychiatry, 36, 233-241. doi: 10.1097/00004583-199702000-00014

Cleckley, H. (1976). The mask of sanity (5 $5^{\text {th }}$ ed.). St. Louis, MO: Mosby.

Costa, P. T., \& McCrae, R. R. (1992). Revised NEO personality inventory (NEO PI-R) and NEP five-factor inventory (NEO-FFI): professional manual: Psychological Assessment Resources.

Fanti, K., Colins, O. F., Andershed, H., \& Sikki, M. (2016). Stability and Change in CallousUnemotional Traits: Longitudinal Associations With Potential Individual and Contextual Risk and Protective Factors. American Journal of Orthpsychiatry. Advance online publication. doi:10.1037/ort0000143

Flom, M., \& Saudino, K. J. (2016). Callous-unemotional behaviors in early childhood: Genetic and environmental contributions to stability and change. Development and Psychopathology. Advance online publication. doi:10.1017/S0954579416001267

Fontaine, N. M. G., Rijsdijk, F. V., McCrory, E. J. P., \& Viding, E. (2010). Etiology of different developmental trajectories of callous-unemotional traits. Journal of the American Academy of Child \& Adolescent Psychiatry, 49, 656-664. doi: 10.1016/j.jaac.2010.03.014

Forget-Dubois, N., Dionne, G., Lemelin, J.-P., Pérusse, D., Tremblay, R. E., \& Boivin, M. (2009). Early Child Language Mediates the Relation Between Home Environment and School Readiness. Child Development, 80, 736-749. doi:10.1111/j.14678624.2009.01294.x

Forget-Dubois, N., Pérusse, D., Turecki, G., Girard, A., Billette, J.-M., Rouleau, G., et al. (2003). Diagnosing zygosity in infant twins: Physical similarity, genotyping, and chorionicity. Twin Research, 6, 479-485. doi: 10.1375/136905203322686464 
Forsman, M., Lichtenstein, P., Andershed, H., \& Larsson, H. (2008). Genetic effects explain the stability of psychopathic personality from mid- to late adolescence. Journal of Abnormal Psychology, 117, 606-617. doi:10.1037/0021-843X.117.3.606

Fowler, T., Langley, K., Rice, F., van den Bree, M., Ross, K., Wilkinson, L. S., . . \& Thapar, A. (2009). Psychopathy trait scores in adolescents with childhood ADHD: The contribution of genotypes affecting MAOA, 5HTT, and COMT activity. Psychiatric Genetics, 19, 312319. doi:10.1097/YPG.0b013e3283328df4

Frick, P. J. (2003). The Inventory of Callous-Unemotional Traits. Unpublished rating scale. The University of New Orleans.

Frick, P. J. (2009). Extending the Construct of Psychopathy to Youth: Implications for Understanding, Diagnosing, and Treating Antisocial Children and Adolescents. Canadian Journal of Psychiatry, 54, 803-812. doi:10.1177/070674370905401203

Frick, P. J., Cornell, A. H., Barry, C. T., Bodin, S. D., \& Dane, H. E. (2003a). Callousunemotional traits and conduct problems in the prediction of conduct problem severity, aggression, and self-report of delinquency. Journal of Abnormal Child Psychology, 31, 457-470. doi:10.1023/A:1023899703866

Frick P. J., Cornell, A. H., Bodin, S. D., Dane, H. E., Barry, C. T., \& Loney, B. R. (2003b). Callous-unemotional traits and developmental pathways to severe conduct problems. Development and Psychopathology, 39, 246-60. doi:10.1037/0012-1649.39.2.246

Frick, P. J., \& Dickens, C. (2006). Current perspectives on conduct disorder. Current Psychiatry Reports, 8, 59-72. doi:10.1007/s11920-006-0082-3

Frick, P. J., \& Hare, R. D. (2001). The Antisocial Process Screening Device. Unpublished rating scale. Multi-Health Systems: Toronto, Canada. 
Frick, P. J., \& Ray, J. V. (2014). Evaluating Callous-Unemotional Traits as a Personality Construct. Journal of Personality, 83, 710-722. doi:10.1111/jopy.12114

Frick, P. J., Ray, J. V., Thornton, L. C., \& Kahn, R. E. (2014). Annual Research Review: A developmental psychopathology approach to understanding callous-unemotional traits in children and adolescents with serious conduct problems. Journal of Child Psychology and Psychiatry, 55, 532-548. doi:10.1111/jcpp.12152

Frick, P. J., Stickle, T. R., Dandreaux, D. M., Farrell, J. M., \& Kimonis, E. R. (2005). Callousunemotional traits in predicting the severity and stability of conduct problems and delinquency. Journal of Abnormal Child Psychology, 33, 471-487. doi:10.1007/s10648005-5728-9

Goldsmith, H. H. (1991). A zygosity questionnaire for young twins: A research note. Behaviour Genetics, 21, 257-269.

Hu, L., \& Bentler, M. (1999). Cutoff criteria for fit indexes in covariance structure analysis: conventional criteria versus new alternatives. Structural Equation Modeling, 5, 1-55. doi:10.1080/10705519909540118

IBM Corp. Released 2011. IBM SPSS Statistics for Windows, Version 20.0 [computer software]. Armonk, NY: IBM Corp.

Kimonis, E. R., Fanti, K. A., Anastassiou-Hadjicharalambous, X., Mertan, B., Goulter, N., \& Katsimicha, E. (2016). Can callous-unemotional traits be reliably measured in preschoolers? Journal of Abnormal Child Psychology, 44, 625-638. doi:10.1007/s10802015-0075-y 
Kimonis, E. R., Frick, P. J., Barry, C. T. (2004). Callous-unemotional traits and deviant peer affiliation. Journal of Consulting and Clinical Psychology, 72, 956-966. doi:10.1037/0022-006X.72.6.956

Lacourse, E., Boivin, M., Brendgen, M., Petitclerc, A., Girard, A., Vitaro, F., Paquin, S., OuelletMorin, I., Dionne, G., \& Tremblay, R. E. (2014). A longitudinal twin study of physical aggression in early childhood: evidence of a developmentally dynamic genome. Psychological Medicine, 44, 2617-2627. doi:10.1017/S0033291713003218

Loeber, R., Pardini, D., Stouthamer-Loeber, M., Hipwell, A. E., \& Sembower, M. (2009). Are there stable factors in girls externalizing behaviors in middle childhood? Journal of Abnormal Child Psychology, 37, 777-791. doi:10.1007/s10802-009-9320-6

Loney, B. R., Taylor, J., Butler, M. A., \& Iacono, W. G. (2007). Adolescent psychopathy features: 6-year temporal stability and the prediction of externalizing symptoms during the transition to adulthood. Aggressive Behavior, 33, 242-252. doi:10.1002/ab.20184

Lynam, D. R., Caspi, A., Moffitt, T. E., Loeber, R., \& Stouthamer-Loeber, M. (2007). Longitudinal evidence that psychopathy scores in early adolescence predict adult psychopathy. Journal of Abnormal Psychology, 116, 155-165. doi:10.1037/0021843X.116.1.155

McArdle, J. J. \& Epstein, D. (1987). Latent Growth Curves within Developmental Structural Equation Models. Child Development, 58, 110-133. doi:10.2307/1130295

McArdle, J. J., \& Hamagami, F. (2003). Structural equation models for evaluating dynamic concepts within longitudinal twin analyses. Behavior Genetics, 33, 137-159. doi:10.1023/A:1022553901851 
McMahon, R. J., Witkiewitz, K., \& Kotler, J. S. (2010). Predictive validity of callousunemotional traits measured in early adolescence with respect to multiple antisocial outcomes. Journal of Abnormal Psychology, 119, 752-763. doi:10.1037/a0020796

Muthén, L. K., \& Muthén, B. O. (1998-2017). Mplus User’s Guide. Eighth Edition. Los Angeles, CA: Muthén \& Muthén.Pardini, D. A., Lochman, J. E., \& Powell, N. (2007). The development of callous-unemotional traits and antisocial behavior in children: Are there shared and/or unique predictors? Journal of Clinical Child and Adolescent Psychology, 36, 319-333. doi:10.1080/15374410701444215

Petitclerc. A., Boivin, M., Dionne, G., Pérusse, D., \& Tremblay, R. E. (2011). Genetic and environmental etiology of disregard for rules. Behavior Genetics, 41, 192-200. doi:10.1007/s10519-010-9393-6

Pingault, J.-B., Rijsdijk, F., Zheng, Y., Plomin, R., \& Viding, E. (2015). Developmentally dynamic genome: evidence of genetic influences on increases and decreases in conduct problems from early childhood to adolescence. Scientific Reports, 5, 10053. doi:10.1038/srep10053

Plomin, R., DeFries, J. C., Knopik, V. S., \& Neiderhiser, J. (2013). Behavioral Genetics (6 ${ }^{\text {th }}$ edition). New York, NY: Worth Publishers.

Plourde, V., Boivin, M., Forget-Dubois, N., Brendgen, M., Vitaro, F., Marino, C., . . Dionne G. (2015). Phenotypic and genetic associations between reading comprehension, decoding skills, and ADHD dimensions: Evidence from two population-based studies. Journal of Child Psychology and Psychiatry, 56, 1074-1082. doi:10.1111/jcpp.12394 
Roose, A., Bijttebier, P., Decoene, S., Claes, L., \& Frick, P. J. (2010). Assessing the affective features of psychopathy in adolescence: A further validation of the Inventory of Callous and Unemotional traits. Assessment, 17, 44-57. doi:10.1177/1073191109344153

Sakai, J. T., Dalwani, M. S., Gelhorn, H. L., Mikulich-Gilbertson, S. K., \& Crowley, T. J. (2012). A behavioral test of accepting benefits that cost others: Associations with conduct problems and unemotionality. PLOS ONE, 7, 1-12. doi:10.1371/journal.pone.0036158

Tuvblad, C., Fanti, K. A., Andershed, H., Colins, O. F., \& Larsson, H. (2016). Psychopathic personality traits in 5 year old twins: the importance of genetic and shared environmental influences. European Child and Adolescent Psychiatry. Advance online publication. doi:10.1007/s00787-016-0899-1

van Baardewijk, Y., Vermeiren, R., Stegge, H., Doreleijers, T. (2011). Self-reported psychopathic traits in children: their stability and concurrent and prospective association with conduct problems and aggression. Journal of Psychopathology and Behavioral Assessment, 33, 263-245. doi:10.1007/s10862-010-9215-4

Viding, E., Fontaine, N. M., Oliver, B. R., \& Plomin, R. (2009). Negative parental discipline, conduct problems and callous-unemotional traits: monozygotic twin differences study. British Journal of Psychiatry, 195, 414-419. doi:10.1192/bjp.bp.108.061192

Viding, E., Hanscombe, K. B., Curtis, C. J. C., Davis, O. S. P., Meaburn, E. L., \& Plomin, R. (2010). In search of genes associated with risk for psychopathic tendencies in children: a two-stage genome-wide association study of pooled DNA. Journal of Child Psychology and Psychiatry, 51, 780-788. doi:10.1111/j.1469-7610.2010.02236.x 
Viding, E., \& McCrory, E. J. (2012). Genetic and neurocognitive contributions to the development of psychopathy. Development and Psychopathology, 24, 969-983. doi:10.1017/S095457941200048X

Viding, E., \& McCrory, E. J. (2015). Developmental risk for psychopathy. In A. Thapar, D. S. Pine, J. F. Leckman, S. Scott, M. J. Snowling, \& E. Taylor (Eds.), Rutter's child and adolescent psychiatry (6th ed., pp. 966-980). Chichester, UK: John Wiley \& Sons, Ltd. doi:10.1002/9781118381953.ch68

Viding, E., Price, T. S., Jaffee, S. R., Trzaskowski, M., David, O. S. P., Meaburn, E. L., Haworth, C. M. A., \& Plomin, R. (2013). Genetics of callous-unemotional behavior in children. PLoS ONE, 8, e65789. doi:10.1371/journal.pone.0065789

Vincent, G. M., Vitacco, M. J., Grisso, T., \& Corrado, R. R. (2003). Subtypes of adolescent offenders: Affective traits and antisocial behavior patterns. Behavioral Science and the Law, 21, 695-712. doi:10.1002/bsl.556 
LONGITUDINAL TWIN CALLOUS-UNEMOTIONAL, 32

Table 1

Descriptive Statistics for Callous-Unemotional Traits at 7, 9, 10 and 12 Years

\begin{tabular}{lcccc}
\hline Variable & $M(S D)$ & Skewness $( \pm 2 * S E)$ & Kurtosis $( \pm 2 * S E)$ & $\alpha$ \\
\hline CU 7 years & $.24(.34)$ & $1.72(1.55-1.89)$ & $2.79(2.45-3.13)$ & .73 \\
CU 9 years & $.27(.39)$ & $1.62(1.45-1.80)$ & $1.97(1.62-2.33)$ & .76 \\
CU 10 years & $.25(.37)$ & $1.87(1.69-2.04)$ & $3.63(3.28-3.98)$ & .75 \\
CU 12 years & $.23(.34)$ & $1.84(1.64-2.03)$ & $3.44(3.05-3.83)$ & .76
\end{tabular}

Note. $\alpha=$ Internal consistency coefficient (alpha); $n=$ Number of participants for each variable.

There was an increase in sample size from ages 9 to 10 years as some families that initially enrolled in the QNTS only provided data from 10 years onwards. 
Table 2

Estimates of Genetic and Environmental Parameters (with 95\% Confidence Intervals) for Full and Nested ACE Models of Callous-Unemotional Traits at 7, 9, 10 and 12 Years

\begin{tabular}{|c|c|c|c|c|c|c|}
\hline & \multicolumn{3}{|c|}{ Parameter Estimates } & \multicolumn{3}{|c|}{ Fit Indices } \\
\hline Age & $a^{2}\left[\mathrm{CI}_{\text {lower }}-\mathrm{CI}_{\text {upper }}\right]$ & $c^{2}\left[\mathrm{CI}_{\text {lower }}-\mathrm{CI}_{\text {upper }}\right]$ & $e^{2}\left[\mathrm{CI}_{\text {lower }}-\mathrm{CI}_{\text {upper }}\right]$ & $-211 \Delta$ & RMSEA & AIC \\
\hline \multicolumn{7}{|l|}{7 years } \\
\hline $\mathrm{ACE}$ & $.46[.30-.61]$ & $.00[.00-.00]$ & $.54[.39-.70]$ & - & .00 & 2299.60 \\
\hline $\mathbf{A E}$ & $.46[.30-.61]$ & - & $.54[.39-.70]$ & .00 & .00 & 2297.61 \\
\hline $\mathrm{E}$ & - & - & $1.00[1.00-1.00]$ & $32.23 *$ & .13 & 2345.08 \\
\hline \multicolumn{7}{|l|}{9 years } \\
\hline $\mathrm{ACE}$ & .59 [.47-.72] & $.00[.00-.00]$ & $.41[.28-.53]$ & - & .00 & 2043.43 \\
\hline $\mathbf{A E}$ & $.59[.47-.72]$ & - & $.41[.28-.53]$ & .00 & .00 & 2041.43 \\
\hline $\mathrm{E}$ & - & - & $1.00[1.00-1.00]$ & $63.94 *$ & .18 & 2123.71 \\
\hline \multicolumn{7}{|l|}{10 years } \\
\hline $\mathrm{ACE}$ & $.39[.22-.57]$ & $.00[.00-.00]$ & $.61[.43-.78]$ & - & .01 & 2161.62 \\
\hline $\mathbf{A E}$ & $.39[.22-.57]$ & - & $.61[.43-.78]$ & .00 & .01 & 2159.62 \\
\hline $\mathrm{E}$ & - & - & $1.00[1.00-1.00]$ & $27.69 *$ & .12 & 2193.91 \\
\hline \multicolumn{7}{|l|}{12 years } \\
\hline $\mathrm{ACE}$ & $.35[-.21-.91]$ & $.13[-.32-.58]$ & $.52[.33-.71]$ & - & .02 & 1714.75 \\
\hline $\mathbf{A E}$ & .50 [.33-.67] & - & .50 [.33-.67] & .33 & .00 & 1713.38 \\
\hline $\mathrm{CE}$ & - & $.38[.25-.52]$ & $.62[.48-.75]$ & 1.35 & .03 & 1715.87 \\
\hline $\mathrm{E}$ & - & - & $1.00[1.00-1.00]$ & $21.66^{*}$ & .14 & 1754.27 \\
\hline
\end{tabular}

Note. Best fitting models are highlighted in bold. All CU scores were age- and sex-regressed. $\mathrm{A}=$ additive genetic factors $\mathrm{C}=$ shared environmental factors; $\mathrm{E}=$ non-shared environmental factors or measurement error; $-211 \Delta=$ differences in -21l (minus two times the log likelihood 
value) values between the fuller model and each reduced model; RMSEA = root mean square error of approximation; AIC = Akaike's index of parsimony. A nested CE model was only tested for the fourth wave, where $\mathrm{C}$ did not equal zero. Fit did not deteriorate in comparison to the full ACE model, but it was still lower than that of the AE model, to which the E model was then compared.

$* p<.001$. 
Table 3

Test Statistics for the Latent Growth Curve and Cholesky Decomposition Models for CallousUnemotional Traits at 7, 9, 10 and 12 Years

\begin{tabular}{lccccc}
\hline Model & $-211 \Delta$ & RMSEA & AIC & BIC & CFI \\
\hline Saturated & - & .01 & 7855.54 & 8061.09 & 1.00 \\
Latent growth curve & 41.09 & .00 & 7840.63 & 7926.28 & 1.00 \\
Cholesky & 32.20 & .00 & 7839.74 & 7942.52 & 1.00 \\
& & & & & \\
\hline
\end{tabular}

Note. All CU scores were age- and sex-regressed. -21l $\Delta=$ scaled differences in -2ll (minus two times the log likelihood value) values between the saturated model and each reduced model; RMSEA = root mean square error of approximation; AIC = Akaike's Information Criterion; BIC $=$ Bayesian Information Criterion; $\mathrm{CFI}=$ Comparative Fit Index . 
Table 4

Latent Growth Curve Model for Callous-Unemotional Traits at 7, 9, 10 and 12 Years $\left(n_{\mathrm{mz}}=218\right.$; $\mathrm{n}_{\mathrm{dz}}=317$ pairs $)$

\begin{tabular}{|c|c|c|c|c|}
\hline & \multicolumn{3}{|c|}{ Unstandardized variance components } & \multirow[t]{2}{*}{ Factors $(\%)$} \\
\hline & A & $\mathrm{C}$ & $\mathrm{E}$ & \\
\hline \multicolumn{5}{|l|}{ Factors } \\
\hline Intercept $(\%)$ & $.63(89)$ & $.17(6)$ & $.15(5)$ & \\
\hline $95 \% \mathrm{CI}$ & $.45-.80$ & $-.29-.62$ & $-.04-.33$ & \\
\hline Slope $(\%)$ & $-.02(0)$ & $-.21(86)$ & $.08(14)$ & \\
\hline $95 \% \mathrm{CI}$ & $-.19-.17$ & $-.31-.10$ & $-.05-.21$ & \\
\hline $\mathrm{G} / \mathrm{E}$ correlations & .00 & .00 & .00 & \\
\hline \multicolumn{5}{|l|}{ Residuals } \\
\hline Wave $1(\%)$ & $.27(7)$ & $.00(0)$ & $.73(51)$ & 42 \\
\hline $95 \% \mathrm{CI}$ & $-.07-.60$ & & $.63-.82$ & \\
\hline Wave $2(\%)$ & $.44(18)$ & $.00(0)$ & $.61(35)$ & 47 \\
\hline $95 \% \mathrm{CI}$ & $.28-.60$ & & $.50-.71$ & \\
\hline Wave $3(\%)$ & $.02(1)$ & $.00(0)$ & $.73(49)$ & 51 \\
\hline $95 \% \mathrm{CI}$ & $-2.67-2.72$ & & $.62-.84$ & \\
\hline Wave $4(\%)$ & $.30(7)$ & $.00(0)$ & $.63(32)$ & 61 \\
\hline $95 \% \mathrm{CI}$ & $-.04-.61$ & & $.49-.77$ & \\
\hline
\end{tabular}

Note. Statistically significant parameters are highlighted in bold. All CU scores were age-

and sex-regressed. $\mathrm{A}=$ Additive genetic component $\mathrm{C}=$ Shared environmental component; $\mathrm{E}=$ Non-shared environmental component; Factors $(\%)=$ Percentage of variance on each wave accounted for by the latent factors (intercept and slope); 95\% CI = 95\% confidence intervals; 
$\mathrm{G} / \mathrm{E}$ correlations $=$ genetic and environmental correlations between the intercept and the slope . Unstandardized estimates are presented; the proportion of variance accounted for is in parentheses. The following parameters were fixed to 0: $\mathrm{C}$ at all waves, $\mathrm{A}, \mathrm{C}$ and $\mathrm{E}$ specific to the Slope. A, C and E correlations between the Intercept and the Slope. 
Table 5

Unstandardized Path Estimates (With 95\% Confidence Intervals) for the Four-Factor Cholesky Decomposition Model for Callous-

Unemotional Traits at 7, 9, 10 and 12 Years $\left(n_{\mathrm{mz}}=218 ; \mathrm{n}_{\mathrm{dz}}=317\right.$ pairs $)$

\begin{tabular}{|c|c|c|c|c|c|}
\hline Age & $\mathrm{A} 1\left[\mathrm{CI}_{\text {lower }}-\mathrm{CI}_{\text {upper }}\right](\%)$ & $\mathrm{A} 2\left[\mathrm{CI}_{\text {lower- }}-\mathrm{CI}_{\text {upper }}\right](\%)$ & $\mathrm{A} 3\left[\mathrm{CI}_{\text {lower- }}-\mathrm{CI}_{\text {upper }}\right](\%)$ & $\mathrm{A} 4\left[\mathrm{CI}_{\text {lower- }}-\mathrm{CI}_{\text {upper }}\right](\%)$ & Total $a^{2}\left[\mathrm{CI}_{\text {lower }}-\mathrm{CI}_{\text {upper }}\right]$ \\
\hline $7 \mathrm{yrs}$ & $.69[.55-.83](47)$ & & & & $.47[.32-.62]$ \\
\hline 9 yrs & $.54[.37-.70](29)$ & .55 [.36-.73] (30) & & & $.59[.47-.71]$ \\
\hline $10 \mathrm{yrs}$ & $.53[.32-.75](28)$ & $.23[-.02-.48](5)$ & $.29[.05-.53](8)$ & & $.41[.25-.56]$ \\
\hline $12 \mathrm{yrs}$ & .35 [.16-.54] (12) & .38 [.14-.62] (14) & $.38[-.08-.84](14)$ & $.36[-.08-.81](13)$ & $.52[.37-.68]$ \\
\hline Age & $\mathrm{E} 1\left[\mathrm{CI}_{\text {lower }}-\mathrm{CI}_{\text {upper }}\right]$ & E2 $\left[\mathrm{CI}_{\text {lower }}-\mathrm{CI}_{\text {upper }}\right]$ & E3 $\left[\mathrm{CI}_{\text {lower }}-\mathrm{CI}_{\text {upper }}\right]$ & $\mathrm{E} 4\left[\mathrm{CI}_{\text {lower }}-\mathrm{CI}_{\text {upper }}\right]$ & Total e2 $\left[\mathrm{CI}_{\text {lower }}-\mathrm{CI}_{\text {upper }}\right]$ \\
\hline $7 \mathrm{yrs}$ & $.74[.64-.84](53)$ & & & & $.53[.38-.68]$ \\
\hline 9 yrs & $.02[-.12-.16](0)$ & $.64[.54-.73](41)$ & & & $.41[.29-.53]$ \\
\hline $10 \mathrm{yrs}$ & $.03[-.11-.17](0)$ & $.13[-.04-.31](2)$ & $.77[.68-.86](57)$ & & $.59[.44-.75]$ \\
\hline $12 \mathrm{yrs}$ & $.13[-.01-.27](2)$ & $.00[-.16-.17](0)$ & $.16[.00-.32](2)$ & $.68[.57-.78](44)$ & $.48[.32-.63]$ \\
\hline
\end{tabular}

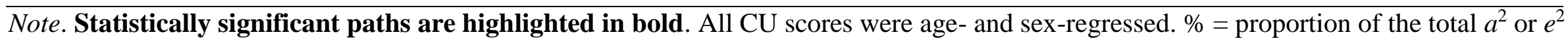
parameter accounted for by the path estimate. 

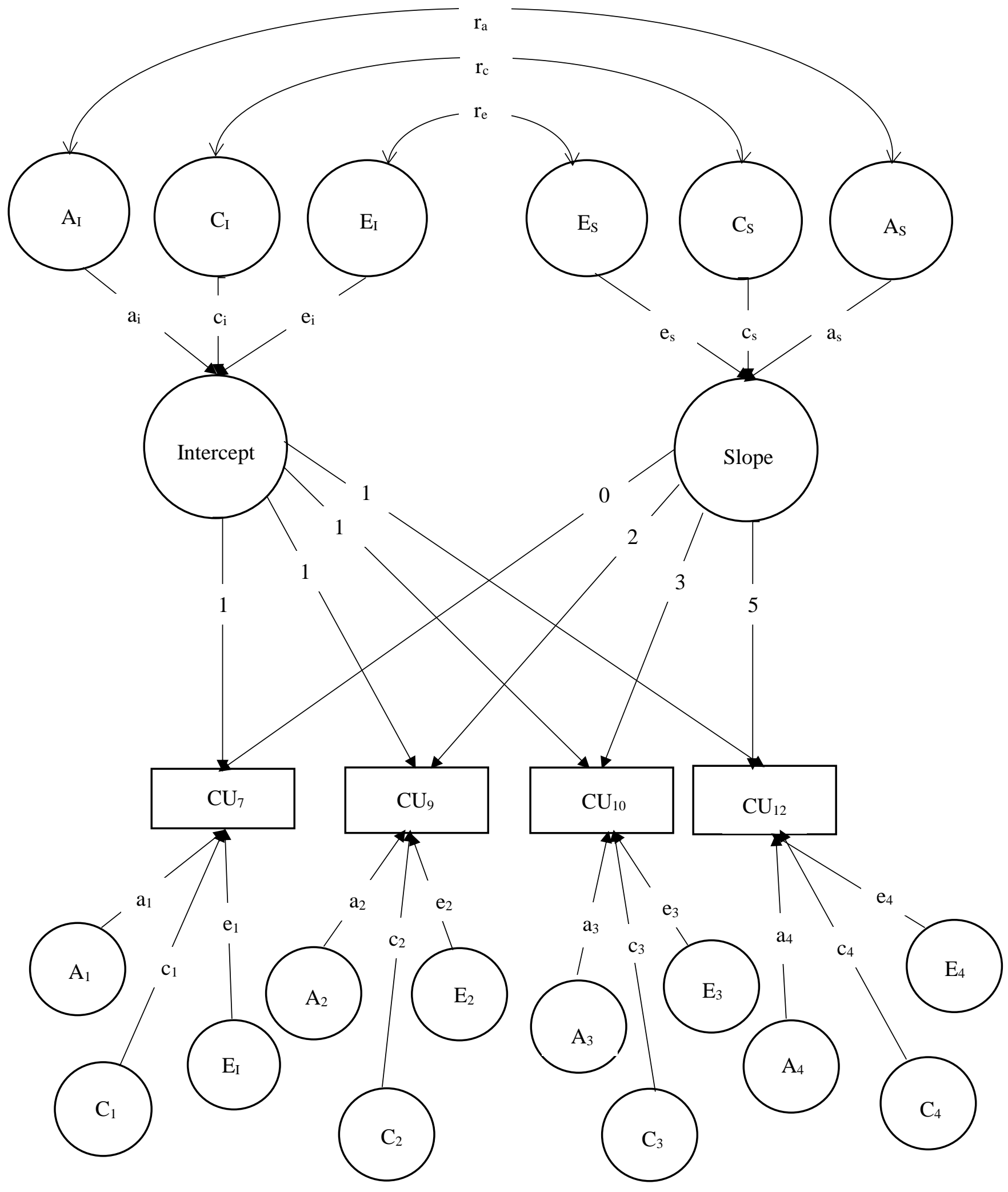
Figure 1. Path Diagram of the Latent Growth Curve Model for Callous-Unemotional (CU) Traits at 7, 9, 10 and 12 years (This diagram represents only one twin in a pair, although the model is identical for the co-twin). 